\title{
Pathogenesis of non-familial colorectal carcinomas with high microsatellite instability
}

\author{
K Shitoh, F Konishi, M Miyaki, T Iijima, T Furukawa, T Tsukamoto, H Nagai
}

\begin{abstract}
Aims-Microsatellite instability (MSI) was first observed in hereditary non-polyposis colorectal carcinoma (HNPCC) and was subsequently seen in non-familial colorectal carcinoma. The relation between MSI and cancer associated genes in nonfamilial colorectal carcinomas has yet to be evaluated. To clarify this matter, changes in cancer associated genes were examined in non-familial colorectal carcinomas.

Methods-Alterations in the adenomatous polyposis coli (APC), p53, and Ki-ras genes were analysed in 24 MSI high (alterations in four to seven of seven loci), nine MSI low (alterations in one to three of seven loci), and 31 MSI negative non-familial carcinomas. The hMSH2 and hMLH1 genes were also analysed in 24 MSI high carcinomas.

Results-Both the frequencies and types of alterations in the APC and p53 genes in MSI high carcinomas were the same as those in MSI low and MSI negative carcinomas; however, they were different from those seen in HNPCC. The frequency of Ki-ras mutation was significantly lower in the MSI high cases (two of $24 ; 8 \%$ ) than in the others $(15$ of $38 ; 39 \%)$. Somatic mutation of hMSH2 or hMLH1 was detected in six of $24(25 \%)$ of the MSI high cases.
\end{abstract}

Department of Surgery, Jichi Medical

School, 3311-1

Yakushiji,

Minamikawachimachi,

Tochigi 324-0498,

Japan

K Shitoh

F Konishi

T Furukawa

H Nagai

Tokyo Metropolitan Komagome Hospital, 3-18-22 Honkomagome Bunkyo-ku, Tokyo

113-8697, Japan

M Miyaki

T Iijima

Department of Pharmacology,

Kitasato University, 5-9-1 Shirogane, Minato-ku, Tokyo

108-8641, Japan

$\mathrm{T}$ Tsukamoto

Correspondence to: Dr Shitoh

kshitoh@)jichi.ac.jp

Accepted for publication 19 April 2000 out MSI, it is thought that the first mutations occur in the APC gene and that chromosomal instability (CI) is the main mechanism. ${ }^{8}$ However, HNPCC results from MSI rather than APC mutations. In addition, the development of most non-familial colon cancers occurs after CI. ${ }^{9}{ }^{10}$ In a previous report, it was proposed that the spectrum of gene mutation in MSI associated cancers (HNPCC) was different from that in CI associated cancers. ${ }^{8}$ In our study, we investigated whether the spectrum of mutations differs between non-familial colorectal carcinomas with MSI and CI associated cancers. ${ }^{11-13}$ Therefore, we compared genetic changes in non-familial colorectal carcinomas with MSI with those without MSI. We compared mutations of the APC, p53, and Ki-ras genes, ${ }^{10} 11$ and also analysed somatic mutations of the hMSH2 and hMLH1 genes in tumours with MSI.

\section{Materials and methods}

Specimens of non-familial colorectal carcinoma and matched normal tissue were obtained from the files of the Jichi Medical School Hospital, Japan. We selected 75 proximal colon carcinomas and 77 distal and rectal carcinomas, and none of the patients had any family history of colorectal carcinoma. Genomic DNA was prepared from fresh carcinomas and matched normal tissue specimens and was then treated by the guanidium/phenol/chloroform method. Twenty four cases (16 proximal, eight distal and rectal) were identified as MSI high carcinomas (defined as alterations in four to seven of seven loci ), and nine cases (seven proximal, two distal and rectal) were MSI low carcinomas (alterations in one to three of seven loci). Of the remaining 119 carcinomas without MSI, 31 cases (21 proximal, 10 distal and rectal) were analysed at random for genetic changes. MSI high carcinomas, MSI low carcinomas, and those without MSI were also compared regarding genetic changes of cancer associated genes. Seven microsatellite markers-D2S123, D2S72, D3S1611, D3S1029, TP53, Mfd26, and BAT26 - were used to determine the MSI status by means of the polymerase chain reaction (PCR). These markers have all been reported in previous studies. ${ }^{14-17}$ The MSI phenotype was determined when at least one band, which was not found in those of the normal mucosa, at one or more loci was present in the PCR products of the carcinomas (fig 1). Clinicopathological features were compared among different grades of MSI status. We classified peritumoral Crohn's like lymphocytic infiltration into three grades $(-,+,++)$. Conspicuous infiltration corresponded to ++ status, and inconspicuous infiltration included - and + status. Lymphatic invasion and venous invasion 
BAT-26

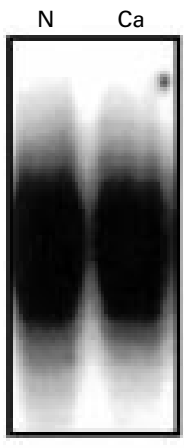

MSI-

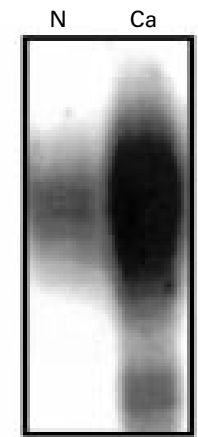

$\mathrm{MSI}+$

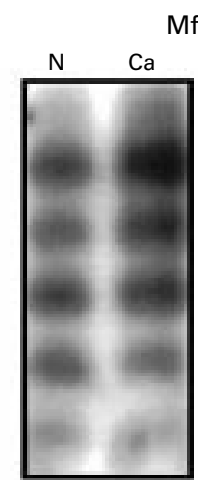

MSI-
Mfd26

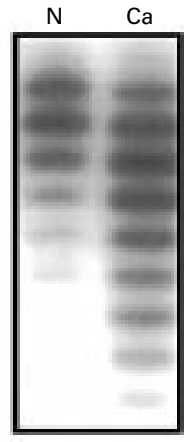

$\mathrm{MSI}+$

TP53

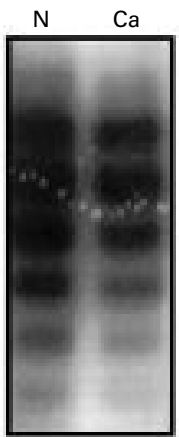

MSI-

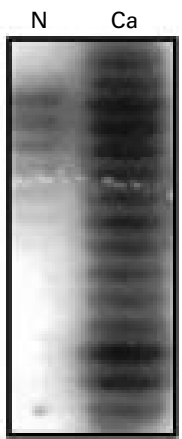

$\mathrm{MSI}+$

Figure 1 MSI negative and positive cases determined using the BAT-26, Mfd26, and TP53 microsatellite markers. N, normal sample; $C a$, carcinoma sample; $M S I-$, MSI negative; $M S I+$, MSI positive.

were classified into four grades according to the Japanese classification of colorectal carcinomas. ${ }^{18}$ Genomic DNA samples of 64 nonfamilial colorectal carcinomas were amplified for single strand conformation polymorphism (SSCP) in APC genes using PCR. ${ }^{19}$ The analysed exons of the APC gene comprised 15A, $15 \mathrm{C}, 15 \mathrm{D}, 15 \mathrm{G}, 15 \mathrm{H}$, and $15 \mathrm{I}$, including the hot spots of somatic mutations. We did not analyse $15 \mathrm{~B}, 15 \mathrm{E}$, and $15 \mathrm{~F}$ because of the low frequency of mutations at these sites. ${ }^{20}$ The primers used for APC were the same as those reported previously. $^{2021}$ For the p53 gene, exons 5-8 were amplified using previously described primers. ${ }^{22}$ Exons 1 and 2 of Ki-ras were analysed to detect mutations in codons 12, 13, and 61. Aberrant single strand DNA fragments were extracted with distilled water from the corresponding bands of a PCR-SSCP gel. The DNA fragments were amplified through the asymmetrical PCR $(100: 1$ or $1: 100)$ using the same primers as those used for PCR-SSCP. The amplified DNAs were purified by the QIAquick spin purification kit (Qiagen, Catsworth, California, USA) and sequenced with the dideoxy chain termination reaction using Sequenase Version 2.0 (United States Biochemical Co, Cleveland, Ohio, USA)

Table 1 Clinicopathological features of microsatellite instability (MSI) high carcinomas and the other cases

\begin{tabular}{|c|c|c|c|}
\hline Feature & MSI high (24) & MSI low (9) & MSI negative (31) \\
\hline \multirow{2}{*}{\multicolumn{4}{|c|}{ Dukes's class }} \\
\hline & & & \\
\hline A & 1 & 1 & 4 \\
\hline B & 12 & 0 & 8 \\
\hline $\mathrm{C}$ & 7 & 6 & 13 \\
\hline $\mathrm{D}$ & 4 & 2 & 6 \\
\hline \multicolumn{4}{|l|}{ Differentiation } \\
\hline Well & 9 & 8 & 18 \\
\hline Moderate & 10 & 1 & 9 \\
\hline Poor & 2 & 0 & 1 \\
\hline Mucinous & 3 & 0 & 3 \\
\hline \multicolumn{4}{|c|}{ Lymphatic invasion } \\
\hline $0-1$ & 18 & 5 & 21 \\
\hline $2-3$ & 6 & 4 & 9 \\
\hline \multicolumn{4}{|l|}{ Venous invasion } \\
\hline $0-1$ & 21 & 7 & 22 \\
\hline $2-3$ & 3 & 2 & 8 \\
\hline \multicolumn{4}{|c|}{ Lymphocytic infiltration } \\
\hline Conspicuous & 6 & 1 & 2 \\
\hline Inconspicuous & 13 & 6 & 17 \\
\hline
\end{tabular}

Results are mean (SD).

Lymphatic invasion: 0, no invasion; 1, mild invasion; 2, moderate invasion; 3, pronounced invasion.

Venous invasion: 0 , no invasion; 1 , mild invasion; 2 , moderate invasion; 3 , pronounced invasion (Japanese classification of colorectal carcinomas).

Lymphocytic infiltration, peritumoral Crohn's like reaction: conspicuous, ++ status; inconspicuous, - and + status. and primers used in PCR-SSCP. Loss of heterozygosity $(\mathrm{LOH})$ on $17 \mathrm{p}$ was detected using the TP53 microsatellite marker and the same PCR and electrophoresis conditions as those used previously for the analysis of microsatellite instability (as described earlier). Some cases were categorised as uninformative because of the nature of MSI - only unequivocal allele patterns were regarded as $\mathrm{LOH}$. Somatic mutations in the hMSH2 and hMLH1 genes among 24 MSI high cases were analysed by PCR-SSCP using the same method as described previously. ${ }^{6}$ After PCR-SSCP, direct sequencing was performed for DNA fragments from aberrant bands as stated earlier. Each exon from 1 to 16 of the hMSH2 gene and each exon from 1 to 19 of hMLH1 was amplified from genomic DNA by PCR using the previously reported primers. ${ }^{23} 24$

\section{Results}

No obvious difference was seen in the clinicopathological features between MSI high cases and other cases (table 1). Using PCR-SSCP, somatic mutation of the APC gene was analysed in 24 MSI high non-familial colorectal carcinomas, nine MSI low carcinomas, and 31 without MSI. When mutant bands were detected in the SSCP gel, DNA fragments extracted from mutant bands were analysed by direct sequencing (fig 2A). Table 2 summarised the results obtained from these analyses. No germline mutation on the APC gene was found. Somatic APC mutations were found in $46 \%$ ( 11 of 24 ) of the MSI high, $44 \%$ of the MSI low, and $32 \%$ of the MSI negative carcinomas, and no obvious differences were observed. In addition, the patterns and distributions did not differ between the MSI high carcinomas and others, and no obvious tendency for mutation was seen in the MSI high carcinomas occurring at the oligonucleotide repeated sequences of the APC gene.

We also analysed the somatic changes at the p53 locus (table 3; fig 2B). The frequencies of p53 somatic mutation and $17 \mathrm{p} \mathrm{LOH}$ in MSI high cases were similar to the other cases. In addition, the distribution and pattern of p53 mutation was similar as was the frequency of carcinomas having $17 \mathrm{p} \mathrm{LOH}$ with $\mathrm{p} 53$ somatic mutations. However, the frequency of $\mathrm{Ki}$-ras mutation was significantly lower in the MSI high cases than in the others (table 4; fig 2C). 
A

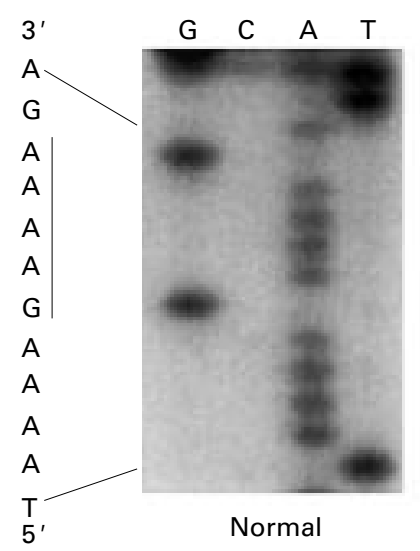

B

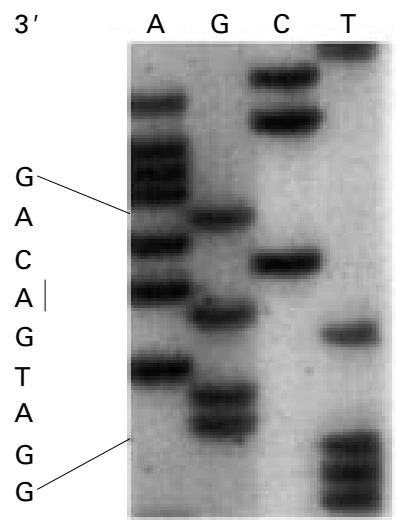

$5^{\prime}$

Normal

C

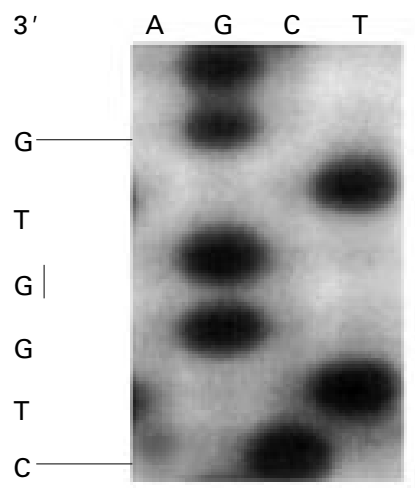

$5^{\prime}$

Normal

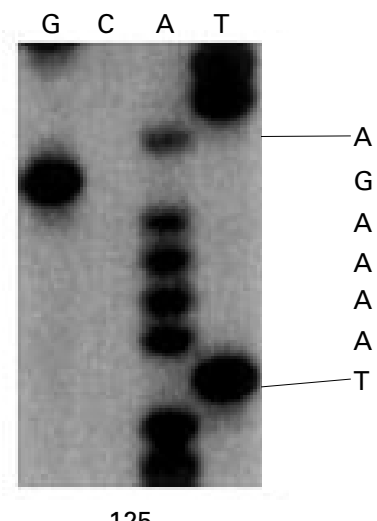

125

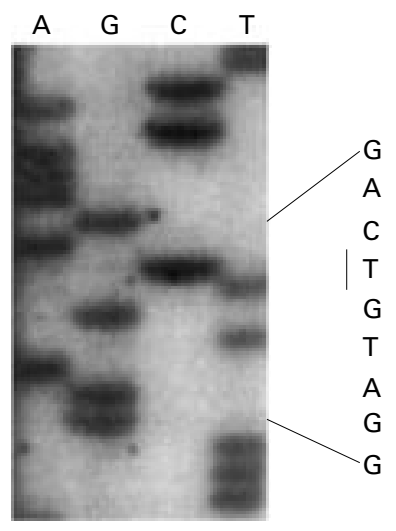

112

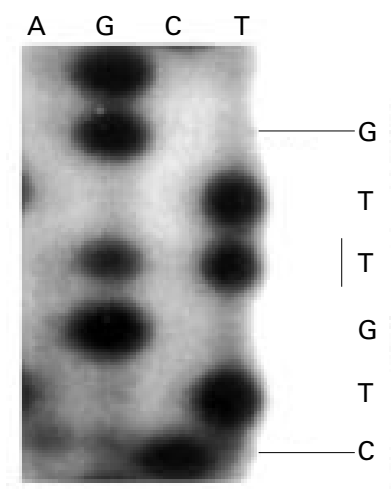

108

Figure 2 DNA sequencing of the APC (adenomatous polyposis coli), $p 53$, and Ki-ras genes. Sequencing of DNA fragments eluted from normal and mutant bands. (A) In number 125, 5 bp (GAAAA) are deleted at codon 1309 in exon 15 of the APC gene. (B) In number 112, $A$ is replaced by $T$ at codon 208 in exon 6 of the p53 gene (amino acid changed from Asp to Val). (C) In number 108, $G$ is replaced by $T$ at codon 12 in exon 1 of the Ki-ras gene (amino acid changed from Gly to Val).

The twenty four MSI high non-familial colorectal carcinomas were analysed for hMSH2 and hMLH1 gene mutations because they were suspected to have defects in the DNA mismatch repair genes. Somatic mutations of hMSH 2 or hMLH1 were found in six cases. Of these six cases, hMSH2 was mutated in one whereas hMLH1 was mutated in the other five (table 5). All six cases with these somatic mutations had no germline mutations in the hMSH2 or hMLH1 genes.

\section{Discussion}

MSI was analysed in 152 non-familial colorectal carcinomas. In many previous reports, the criteria for the selection of non-familial colorectal carcinomas has not been stringent. ${ }^{11-13} \mathrm{We}$ excluded all cases with colorectal carcinoma in first degree relatives. We classified MSI into MSI high (alterations in four to seven of seven loci), and MSI low (alterations in one to three of seven loci), and focused only on carcinomas showing high frequency MSI. Such a separation into high and low frequency MSI seems to be important for assessing the contribution of "true" MSI in the carcinogenesis of nonfamilial cases. The clinicopathological features of our MSI high cases were not different from those of MSI low and MSI negative cases. The nature of MSI high non-familial colorectal carcinomas might be considered to be different from that of HNPCC (table 1).

We have previously found the frequencies of mutations among APC, p53, and Ki-ras in HNPCC tumours with MSI to be lower than in non-familial colorectal carcinomas. ${ }^{6}$ However, it was not clear whether these mutation frequencies were lower in MSI high non-familial colorectal carcinoma. Our results revealed that APC mutations in MSI high non-familial colorectal carcinoma were not substantially different from MSI low and MSI negative carcinomas with regard to frequency, type, and distribution within the gene. Although our results are consistent with those reported by Homfray et $a l,{ }^{13}$ the cases in their study included carcinomas with MSI at one locus only. There have been other reports on the association between APC mutation and MSI status in non-familial cases. Olschwang et al and Jass et al reported the frequency of mutations or LOH in APC genes to be less in replication error (RER) positive than in RER negative carcinomas. ${ }^{11}{ }^{25}$ Konishi et al reported that no APC mutations were present in four cases of sporadic carcinoma with severe RER $^{6}$ and Salahshor et al mentioned the low frequency of APC mutations in MSI high carcinomas. ${ }^{26}$ It is unclear why our present results are different from those of previous reports. The contamination of HNPCC cases in previous reports might be one possible reason for these discrepancies. However, this is unlikely because of the small proportion of HNPCC among colorectal carcinoma in general. Our results suggest that APC mutation initiates tumorigenesis irrespective of MSI status in nonfamilial cases, and thus closely correlate with the assumptions of Tomlinson et al. ${ }^{27}$

Our study also revealed that the frequency of p53 mutation did not substantially differ between MSI high, MSI low, and MSI negative non-familial colorectal carcinomas. Lleonart et al also reported no correlation between MSI and p53 mutations in sporadic colon carcinomas. ${ }^{28}$ Olschwang et al found no difference in the frequency of p53 mutation between RER positive and RER negative carcinomas, but the frequency of $17 \mathrm{p} \mathrm{LOH}$ in RER positive carcinomas was significantly lower than that in RER negative carcinomas. ${ }^{11}$ Simms et al and Salahshor et al mentioned the low frequency of p53 mutation and Jass et al reported the low 
frequency of $17 \mathrm{p}$ LOH in MSI high cancers. ${ }^{25} 26{ }^{29}$ In previous reports, the frequency of abnormal p53 immunohistochemistry in MSI high cancers was low. ${ }^{26}{ }^{30-34} \mathrm{We}$ thought that such differences might result from the inadvertent inclusion of familial cases; however, the reasons for the differences are still unclear. In our cases, the frequency of $17 \mathrm{p} \mathrm{LOH}$ was as high in MSI high carcinomas as in MSI low and MSI negative carcinomas, thus suggesting that alterations in two alleles of the p53 gene contribute to carcinogenesis in non-familial cases, irrespective of MSI status. Ki-ras mutations were much less frequent in MSI high non-familial colorectal carcinomas than in MSI low and MSI negative carcinomas. In some cases, high MSI might have

Table 2 List of somatic mutations at the adenomatous polyposis coli (APC) gene

\begin{tabular}{|c|c|c|c|c|c|}
\hline Case & MSI & Codon & Type & Nomenclature & Base change \\
\hline 1 & ++ & 1449 & DEL1 & Frame & $\mathrm{AAG} \rightarrow \mathrm{AG}$ \\
\hline 18 & ++ & 1465 & DEL1 & Frame & AGAGT $\rightarrow$ AGGT \\
\hline 39 & ++ & 1336 & DEL7 & Frame & AGACTGCAG $\rightarrow$ AG \\
\hline 53 & ++ & 1465 & DEL1 & Frame & AGAGT $\rightarrow$ AGGT \\
\hline \multirow[t]{2}{*}{72} & ++ & 889 & NS & NS & $\mathrm{AAA} \rightarrow \mathrm{TAA}$ \\
\hline & & 1450 & NS & NS & $\mathrm{CGA} \rightarrow \mathrm{TGA}$ \\
\hline 73 & ++ & 665 & DEL2 & Frame & $\mathrm{TTA} \rightarrow \mathrm{A}$ \\
\hline 75 & ++ & 665 & DEL2 & Frame & $\mathrm{TTA} \rightarrow \mathrm{A}$ \\
\hline 78 & ++ & 1336 & DEL7 & Frame & AGACTGCAG $\rightarrow$ AG \\
\hline 82 & ++ & 1557 & INS1 & Frame & $\mathrm{ACT} \rightarrow \mathrm{ACCT}$ \\
\hline 125 & ++ & 1309 & DEL5 & Frame & GAAAGATT $\rightarrow$ GATT \\
\hline 148 & ++ & 1308 & DEL8 & Frame & ATAAAAGAAAA $\rightarrow$ ATA \\
\hline 27 & + & 1450 & NS & NS & $\mathrm{CGA} \rightarrow \mathrm{TGA}$ \\
\hline 31 & + & 1450 & NS & NS & $\mathrm{CGA} \rightarrow \mathrm{TGA}$ \\
\hline 64 & + & 1453 & DEL1 & Frame & $\mathrm{CCT} \rightarrow \mathrm{CT}$ \\
\hline 83 & + & 1450 & INS1 & Frame & $\mathrm{CGA} \rightarrow \mathrm{CCGA}$ \\
\hline 12 & - & 1320 & DEL5 & Frame & AAGATTG $\rightarrow$ AA \\
\hline 15 & - & 1469 & NS & NS & $\mathrm{CAA} \rightarrow \mathrm{TAA}$ \\
\hline 24 & - & 1309 & DEL5 & Frame & GAAAAGATT $\rightarrow$ GATT \\
\hline \multirow[t]{2}{*}{26} & - & 917 & DEL1 & Frame & $\mathrm{GAT} \rightarrow \mathrm{GT}$ \\
\hline & & 1464 & DEL4 & Frame & GAGAGT $\rightarrow$ GT \\
\hline 66 & - & 1451 & INS2 & Frame & GAA $\rightarrow$ GGGAA \\
\hline 68 & - & 1336 & DEL7 & Frame & AGACTGCAG $\rightarrow$ AG \\
\hline 77 & - & 1336 & DEL7 & Frame & AGACTGCAG $\rightarrow$ AG \\
\hline 106 & - & 736 & NS & NS & $\mathrm{AAG} \rightarrow \mathrm{TAG}$ \\
\hline 108 & - & 895 & NS & NS & $\mathrm{TCA} \rightarrow \mathrm{TAA}$ \\
\hline 109 & - & 1557 & INS1 & Frame & $\mathrm{ACT} \rightarrow \mathrm{ACCT}$ \\
\hline
\end{tabular}

MSI, microsatellite instability; MSI++, MSI high; MSI+, MSI low; MSI-, MSI negative; DEL, deletion; INS, insertion; NS, nonsense mutation; Frame, frameshift mutation.

Table 3 Details of cases with p53 mutations

\begin{tabular}{|c|c|c|c|c|c|c|c|}
\hline \multirow[b]{2}{*}{ Case } & \multirow[b]{2}{*}{$M S I$} & \multirow[b]{2}{*}{ p53 LOH } & \multicolumn{5}{|c|}{ p53 mutation } \\
\hline & & & Exon & Codon & Base change & Nomenclature & Amino acid change \\
\hline 29 & ++ & NI & 6 & 198 & $\mathrm{GAA} \rightarrow \mathrm{CAA}$ & Mis & Arg $\rightarrow$ His \\
\hline 39 & ++ & + & 5 & 175 & $\mathrm{CGC} \rightarrow \mathrm{CAC}$ & Mis & $\mathrm{Arg} \rightarrow \mathrm{His}$ \\
\hline 72 & ++ & + & 5 & $132-136$ & $16 \mathrm{bp}$ del & Frame & Stop at 164 \\
\hline 82 & ++ & - & 7 & 248 & $\mathrm{CGG} \rightarrow \mathrm{TGG}$ & Mis & $\operatorname{Arg} \rightarrow \operatorname{Trp}$ \\
\hline 102 & ++ & + & 5 & 175 & $\mathrm{CGC} \rightarrow \mathrm{CAC}$ & Mis & $\mathrm{Arg} \rightarrow \mathrm{His}$ \\
\hline 151 & ++ & + & 5 & 146 & $\mathrm{TGG} \rightarrow \mathrm{TCG}$ & Mis & Trp $\rightarrow$ Ser \\
\hline 27 & + & + & 5 & 147 & $1 \mathrm{bp}$ ins & Frame & Stop at 148 \\
\hline 31 & + & + & 6 & 205 & $\mathrm{TAA} \rightarrow \mathrm{AAT}$ & Mis & Tyr $\rightarrow$ Asn \\
\hline 15 & - & + & 8 & 273 & $\mathrm{CGT} \rightarrow \mathrm{CAT}$ & Mis & $\mathrm{Arg} \rightarrow \mathrm{His}$ \\
\hline 26 & - & - & 5 & 170 & $\mathrm{ACG} \rightarrow \mathrm{TCG}$ & Mis & $\mathrm{Thr} \rightarrow \mathrm{Ser}$ \\
\hline 30 & - & + & 5 & 175 & $\mathrm{CGC} \rightarrow \mathrm{CAC}$ & Mis & $\mathrm{Arg} \rightarrow \mathrm{His}$ \\
\hline 67 & - & NI & 6 & 221 & $\mathrm{GAG} \rightarrow \mathrm{CAG}$ & Mis & $\mathrm{Glu} \rightarrow \mathrm{Gln}$ \\
\hline 69 & - & - & 5 & 170 & $\mathrm{ACG} \rightarrow \mathrm{TCG}$ & Mis & $\mathrm{Thr} \rightarrow \mathrm{Ser}$ \\
\hline 77 & - & + & 5 & 175 & $\mathrm{CGC} \rightarrow \mathrm{CAC}$ & Mis & $\mathrm{Arg} \rightarrow \mathrm{His}$ \\
\hline 109 & - & + & 5 & 175 & $\mathrm{CGC} \rightarrow \mathrm{CAC}$ & Mis & Arg $\rightarrow$ His \\
\hline 110 & - & - & 7 & 248 & $\mathrm{CGG} \rightarrow \mathrm{CTG}$ & Mis & $\mathrm{Arg} \rightarrow \mathrm{Leu}$ \\
\hline 111 & - & + & 8 & 273 & $\mathrm{CGT} \rightarrow \mathrm{CAT}$ & Mis & $\mathrm{Arg} \rightarrow \mathrm{His}$ \\
\hline 112 & - & + & 6 & 208 & $\mathrm{GAC} \rightarrow \mathrm{GTC}$ & Mis & $\mathrm{Asp} \rightarrow \mathrm{Val}$ \\
\hline 136 & - & + & 8 & 282 & $\mathrm{CGG} \rightarrow \mathrm{TGG}$ & Mis & $\operatorname{Arg} \rightarrow \operatorname{Trp}$ \\
\hline
\end{tabular}

MSI, microsatellite instability; MSI++, MSI high; MSI+, MSI low; MSI-, MSI negative; NI, not informative; bp, base pair; del, deletion; ins, insertion; $\mathrm{LOH}$, loss of heterozygosity; $\mathrm{LOH}+$, LOH positive; $\mathrm{LOH}-$, LOH negative; Mis, Missense mutation; Frame, Frameshift mutation.

Table 4 Summary of frequency of somatic changes in microsatellite instability (MSI) high, MSI low, and MSI negative non-familial colorectal carcinomas

\begin{tabular}{|c|c|c|c|c|c|c|}
\hline \multirow[b]{3}{*}{ MSI type } & \multirow[b]{3}{*}{$\begin{array}{l}\text { No. of tumours } \\
\text { analysed }\end{array}$} & \multicolumn{5}{|c|}{ No. of tumours with somatic changes } \\
\hline & & \multicolumn{3}{|c|}{ Mutation/informative tumours (\%) } & \multicolumn{2}{|c|}{ LOH/informative tumours (\%) } \\
\hline & & $A P C$ & $p 53$ & Ki-ras & $17 p$ & $\begin{array}{l}\text { LOH of } 17 p / p 53 \\
\text { mutation (\%) }\end{array}$ \\
\hline MSI high & 24 & $11 / 24(46)$ & $6 / 22(27)$ & $2 / 24(8)$ & 9/23 (39) & $4 / 6(67)$ \\
\hline MSI low & 9 & $4 / 9(44)$ & $2 / 7(28)$ & $4 / 9(44)$ & $4 / 8(50)$ & $1 / 2(50)$ \\
\hline MSI negative & 31 & $10 / 31(32)$ & $11 / 29(38)$ & $11 / 29(38)$ & $11 / 26(42)$ & $7 / 11(64)$ \\
\hline p Value, MSI high $v$ MSI low and & MSI negative & 0.4 & 0.4 & 0.008 & 0.68 & $>0.999$ \\
\hline
\end{tabular}

Sequence accession numbers by Genebank (APC, M74088; p53, M14694; Ki-ras, M34904).

$\mathrm{LOH}$, loss of heterozygosity. 
Table 5 Somatic mutations of $h M S H 2$ and $h M L H 1$ genes in microsatellite instability (MSI) high cases

\begin{tabular}{lllll}
\hline Case & Gene & Affected codon & DNA change & Nomenclature of mutation \\
\hline 72 & hMSH2 & 754 & ins G & Frameshift to stop at 786 \\
78 & hMLH1 & 163 & TAC-TAA & Nonsense \\
148 & hMLH1 & 179 & ins G & Frameshift to stop at 197 \\
151 & hMLH1 & 291 & TTG-TAG & Nonsense \\
121 & hMLH1 & 425 & GAT-GGT & Missense from Asp to Gly \\
102 & hMLH1 & 320 & ins C & Frameshift to stop at 361 \\
\hline
\end{tabular}

Sequence accession numbers by Genebank (hMLH1, U07418; hMSH2, U03911). ins, insertion.
7 Kinzler KW, Vogelsrein B. Landscaping the cancer terrain. Science 1998;280:1036-37.

8 Cahill DP, Lengauer C, Yu J, et al. Mutations of mitotic checkpoint genes in human cancers. Nature 1998;392:2234.

9 Vogelstein B, Fearon ER, Hamilton SR, et al. Genetic alterations during colorectal-tumor development. $N$ Engl F Med 1988;319:525-32.

10 Miyaki M, Seki M, Okamoto M, et al. Genetic changes and histopathological types in colorectal tumors from patients with familial adenomatous polyposis. Cancer Res 1990;50: 7166-73.

11 Olschwang S, Hamelin R, Laurent-Puig P, et al. Alternative genetic pathways in colorectal carcinogenesis. Proc Natl genetic pathways in colorectal carc
Acad Sci U S A 1997;94:12122-7.

12 Huang J, Papadopoulos N, McKinley AJ, et al. APC mutations in colorectal tumors with mismatch repair deficiency. Proc Natl Acad Sci U S A 1996;93:9049-54.

13 Homfray TFR, Cottrell SE, Rowan A, et al. Defects in mismatch repair occur after APC mutation in the pathogenesis of sporadic colorectal tumours. Hum Mutat 1998;11:11420 .

14 Senba S, Konishi F, Okamoto T, et al. Clinicopathologic and genetic features of nonfamilial colorectal carcinomas with DNA replication errors. Cancer 1998;82:279-85.

15 Shitoh K, Konishi F, Masubuchi S, et al. Important microsatellite markers in the investigation of replication errors (RER) in colorectal carcinomas. fpn f Clin Oncol 1998;28: 538-41.

16 Hoang JM, Cottu PH, Thuille B, et al. BAT26, an indicator of the replication error phenotype in colorectal cancers and cell lines. Cancer Res 1997;57:300-3.

17 Dietmaier W, Wallinger S, Bocker T, et al. Diagnostic microsatellite instability: definition and correlation with mismatch repair protein expression. Cancer Res 1997;57: 4749-56.

18 Japanese Society for Cancer of the Colon and Rectum. fapanese classification of colorectal carcinoma. Tokyo: Kanehara and Company Ltd, 1997.

19 Orita M, Suzuki Y, Sekiya T, et al. Rapid and sensitive detection of point mutations and DNA polymorphism using the polymerase chain reaction. Genomics 1989;5:874-9.

20 Miyaki M, Konishi M, Kikuchi-Yanoshita R, et al. Characteristic of somatic mutation of the adenomatous polyposis coli gene in colorectal tumors. Cancer Res 1994;54:3011-20.

21 Groden J, Thliveris A, Samowitz W, et al. Identification and characterization of the familial adenomatous polyposis coli gene. Cell 1991;66:589-600.

22 Kikuchi-Yanoshita R, Konishi M, Ito S, et al. Genetic changes in both p53 alleles associated with the conversion from colorectal adenoma to early carcinoma in familial adenomatous polyposis and non-familial adenomatous polyposis patients. Cancer Res 1992;52:3965-71.

23 Liu B, Parsons RE, Hamilton SR, et al. hMSH2 mutations in hereditary nonpolyposis colorectal cancer kindreds. Cancer Res 1994;54:4590-94.

24 Kolodner RD, Hall NR, Lipford J, et al. Structure of the human MSH2 locus and analysis of two Muir-Torre kinders for msh2 mutations. Genomics 1994;24:516-26.

25 Jass JR, Biden KG, Cummings MC, et al. Characterisation of a subtype of colorectal cancer combining features of the suppressor and mild mutator pathways. F Clin Pathol 1999; 52:455-60.

26 Salahshor S, Kressner U, Pahlman L, et al. Colorectal cancer with and without microsatellite instability involves different genes. Genes Chromosomes Cancer 1999;26:247-52.

27 Tomlinson IPM, Novelli MR, Bodmer WF. The mutation rate and cancer. Proc Natl Acad Sci U S A 1996;93:14800-3.

28 Lleonart ME, Foncillas JG, Prieto RS, et al. Microsatellite instability and p53 mutations in sporadic right and left colon carcinoma. Cancer 1998;83:889-95.

29 Simms LA, Radford-Smith G, Biden KG, et al. Reciprocal relationship between the tumor suppressors p53 and BAX in primary colorectal cancers. Oncogene 1998;17:2003-8.

30 Forster S, Sattler HP, Hack M, et al. Microsatellite instability in sporadic carcinomas of the proximal colon: association with diploid DNA content, negative protein expression of $\mathrm{p} 53$, and distinct histomorphologic features. Surgery 1998;123:13-18.

31 Muta $\mathrm{H}$, Noguchi M, Perucho M, et al. Clinical implications of microsatellite instability in colorectal cancers. Cancer 1996;77:265-70.

32 Fujiwara T, Stolker JM, Watanabe T, et al. Accumulated clonal genetic alterations in familial and sporadic colorectal carcinomas with widespread instability in microsatellite sequences. Am f Pathol 1998;153:1063-78.

33 Biden KG, Simms LA, Cummings M, et al. Expression of $\mathrm{Bcl}-2$ protein is decreased in colorectal adenocarcinomas with microsatellite instability. Oncogene 1999;18:1245-9.

34 Kojima M, Konishi F, Tsukamoto $\mathrm{T}$, et al. Ki-ras point mutation in different types of colorectal carcinomas in early stages. Dis Colon Rectum 1997;40:161-7.

35 Okamoto T, Konishi F, Kojima M, et al. Significance of microsatellite instability in different types of early-stage nonfamilial colorectal carcinomas. Dis Colon Rectum 1998; 41:1385-9.

Konishi M, Kikuchi-Yanoshita R, Tanaka K, et al. Molecular nature of colon tumors in hereditary nonpolyposis colon cancer, familial polyposis, and sporadic colon cancer. Gas troenterology 1996;111:307-17. 